\title{
A cross-sectional survey of a public, evidence-based multimodal program for cognitive health in older adults
}

\author{
Barbara Studer-Luethi $^{1^{*}}$ D, Maria Brasser ${ }^{2}$, Simon Lusti ${ }^{1}$ and Rahel Schaerli ${ }^{1}$
}

\begin{abstract}
Background: In recent decades, the proportion of older adults in the population has continued to rise, and with it, the need for intervention programs to maintain cognitive functions into old age. Multiple lifestyle factors, including physical, cognitive, and social activities, are crucial to forestalling a decline in cognitive functions. However, Covid19 curtailed most activities, and therefore, strategies are needed to support older adults in remaining cognitively healthy. This study describes a newly developed and publicly available multimodal program, called "brain coach", to support and stimulate cognitive activity in older adults. The autonomy supportive program integrates into daily life recommendations for evidence-based physical, cognitive, social, mindful, and creative activation exercises.
\end{abstract}

Methods: The study design corresponds to a correlational, analytical, and cross-sectional study with 660 older adults, who participated in the program for at least 3 months and completed an online survey.

Results: The survey results demonstrate that the average age of the participants was 71 years and $75 \%$ were female. Participants experienced benefits in memory, well-being, attitudes towards the brain, and lifestyle habits. Importantly, time invested in the intervention and participant's positive attitude toward brain health and neuroplasticity, show positive relationships with the experienced benefits.

Conclusions: The results reveal the potential of a public program with a multimodal approach to increase cognitive health and promote an active lifestyle. Further research will explore the effects of such a multimodal intervention in a longitudinal randomized controlled trial study.

Keywords: Cognitive health, Public prevention, Multimodal intervention, Cognitive stimulation

\section{Background}

The ability to think, learn, and remember is essential to performing everyday activities and living independently. Therefore, as we age, one important goal is to maintain this general cognitive health. Because the proportion of older individuals in the general population continues to increase (United Nations, [64]), the demand for effective programs that support individuals in preventing cognitive decline is also growing. In addition, the adult brain

\footnotetext{
* Correspondence: barbara.studer@psy.unibe.ch

${ }^{1}$ University of Bern, Bern, Switzerland

Full list of author information is available at the end of the article
}

structure has a great capacity to adapt and change in response to experience and training [19], so preventative approaches are promising.

Encouragingly, research findings from the previous two decades have shown that non-biological factors and lifestyle strongly influence cognitive decline [26]. That is, several lifestyle changes are crucial for cognitive health, including physical, cognitive, and social activities. Also, regulations imposed in response to Covid-19 have restricted various opportunities for cognitively stimulating activities, such as cultural events and other social interactions. Thus, interventions supporting and guiding

C C The Author(s). 2021 Open Access This article is licensed under a Creative Commons Attribution 4.0 International License, which permits use, sharing, adaptation, distribution and reproduction in any medium or format, as long as you give appropriate credit to the original author(s) and the source, provide a link to the Creative Commons licence, and indicate if changes were made. The images or other third party material in this article are included in the article's Creative Commons licence, unless indicated otherwise in a credit line to the material. If material is not included in the article's Creative Commons licence and your intended use is not permitted by statutory regulation or exceeds the permitted use, you will need to obtain permission directly from the copyright holder. To view a copy of this licence, visit http://creativecommons.org/licenses/by/4.0/ The Creative Commons Public Domain Dedication waiver (http://creativecommons.org/publicdomain/zero/1.0/) applies to the data made available in this article, unless otherwise stated in a credit line to the data. 
older adults in their daily cognitive activities are even more important to protect them from cognitive decline. In addition, the advantages of web-based interventions became more obvious and technology acceptance increased. This is favorable, as a growing research field reveals the potential of technology and web-based interventions to enhance and enrich the lives of older adults. That is, use of technology can facilitate better interpersonal relationships, social connectedness, and physical health, which can be a substantial benefit for older adults ([1]; Chopik, [17]; Rogers \& Mitzner, [53]).

The present investigation follows Williams and Camper's (2010) appeal that "older adults may be advised to add new cognitive, physical, and social activities, and improved nutrition to support successful cognitive aging and to improve neuroplasticity." That is, this study describes and investigates a public autonomy supportive online program for cognitive health by determining what kind of individuals participate in such a program, how much time they spend on the exercises, and whether they experience any benefits from the intervention. The implemented program offers support in maintaining cognitive health by sending registered individuals recommendations for evidence-based activities, lifestyle advice, and background information about the aging brain. The newly developed program emphasis the multimodality of effective prevention of cognitive decline by considering the evidence-based crucial lifestyle factors, which will be described in the following.

\section{Crucial lifestyle factors that prevent cognitive decline}

A growing body of scientific research and the resulting World Health Organization (WHO) guidelines [4] have identified several crucial lifestyle factors that reduce the risk of cognitive decline and dementia.

The first factor is actively taking care of physical health by healthy food intake [46] and regular physical exercise [11]. individuals who are obese in midlife have a higher risk of dementia than those of healthy body weight. Indeed, both healthy food and physical exercise modulate the cellular and molecular processes in the brain vital for cognitive health, including optimizing growth factors such as brain-derived neurotrophic factors (e.g., [15]). In addition, intervention studies have shown that physical activity and optimized dietary behaviors increase cognitive functioning in older age. Increased physical activity is beneficial in protecting against cognitive decline [56].

The second factor is cognitive activity, such as lifelong learning and intellectual engagement. Higher cognitive activity in midlife and later life associates with delayed onset of cognitive impairment [66]. Cognitive interventions aim either to train memory and other cognitive processes directly or to train memory strategies that, in turn, improve cognitive performance [9]. Findings regarding the effects of cognitive interventions on the general cognitive functions of older adults are inconclusive (for a recent review, see [55]). Some cognitive interventions demonstrated significant benefits and indicated some transfer to daily life in healthy older adults $[5,9$, 62 ] or older adults with mild cognitive impairments or dementia [73]. However, other cognitive interventions produced no significant benefits on the cognitive performance of older adults (e.g. [2]).

Another crucial factor is social activity. Few social contacts and low social have been associated with increased dementia risk [31]. Research has confirmed the importance of social connection through social activities to protect from cognitive decline and reduce feelings of isolation and loneliness (see [12, 42], for a metaanalysis). Various intervention studies have shown the positive effect of social activities on cognitive variables (e.g., [6, 18], for a meta-analysis). For example, a study of older adults with dementia revealed the positive influence of communication with family members and healthcare professionals on patients' behavior and symptoms [67].

A range of other factors also influence cognitive function in older adults. One of them is mindfulness, which is associated with lower perceived stress and cortisol levels and improved well-being (cf. [25]). Because chronic stress affects memory and increases the risk of dementia [44], mindfulness-based interventions protect cognitive health (cf. [16]). In addition to this indirect effect on cognition through improved physiological mechanisms related to stress and immune function, a direct effect may occur through the repeated activation of attentional functions [39]. Indeed, evidence has shown that mindfulness-based interventions improve cognition in older adults with and without mild cognitive impairment $[68,74]$.

Another factor is creativity, linked to mental and physiological health indicators and cognition in older age (e.g., [58]). Individuals that frequently engage in highly creative activities demonstrate higher cognitive reserve than individuals with more routine activities [20]. Intervention studies with older adults with and without mild cognitive impairment or dementia found more significant positive effects on cognitive functions and daily living ability after creative therapy (e.g., drawing, dance, music, storytelling) than after standard cognitive training [41, 75]. In addition to interventions traditionally identified as creative, other creative activities include idea generation and improvising (cf. [22]).

Finally, humor leads to the release of endorphins in the brain and a reduction of cortisol, which produces psychological and physiological effects similar to the benefits of aerobic exercise (cf. [8]). Also, humor is a form of cognitive reappraisal, allowing individuals to 
reappraise daily stressors. Therefore, humor may decrease stress and protect cognitive abilities in older adults (cf. [40]). Humor interventions relieve chronic pain and enhance happiness and life satisfaction (e.g. [63]).

\section{A new autonomy-supportive multimodal program for cognitive health}

"Brain coach" is a new public multimodal program that combines all the evidence-based factors mentioned above. It does so, because research on cognitive health suggests that the effect of these lifestyle factors on cognitive fitness may be additive and that a generally active lifestyle seems more effective than specific short-term interventions [32]. That is, single-component interventions often result in task-specific improvements with minimal, if any, generalization to overall cognitive functioning and daily life situations (e.g. [27, 52]). By comparison, multimodal interventions may produce more significant benefits by addressing multiple factors [14].

The present "brain coach" program reflects an autonomy-supportive intervention to increase autonomous motivation to invest in health behavior, which, based on the self-determination theory, can be reached by affording autonomy, relatedness, and competence of participants [54]. On this basis, the program aims to enable older adults and facilitate behavioral change through education, training, and relatedness (cf. [23, 60, $61,76]$ ). Also, the program aims to increase the awareness of brain health, because previous research has highlighted this need, as the general knowledge of dementia is inadequate $[13,24]$.

That is, the program informs participants about neuroplasticity and the impact of their lifestyle on their cognitive health (i.e., education). Participants receive weekly exercise recommendations for physical, cognitive, social, mindful, and creative activities for daily life (i.e., training). Participants can exchange and share their goals and experiences in a supervised online forum (i.e., relatedness).

\section{The present study}

Whereas some existing lifestyle interventions combine two or three lifestyle factors, such as physical exercise and cognitive training $[38,48]$, little is known about effects of $\mathrm{s}$ multimodal program which include all the above-mentioned lifestyle factors. Also, there is only scarce evidence of personal characteristics that may influence cognitive intervention outcomes. One of them is stereotypes of older adults, such as the prevalent perception that they are cognitively impaired and forgetful (e.g., [71]). Such stereotypes were shown to negatively affect performance of older adults [33] and increase dementia worry [45]. Similarly, the belief in the brain's capacity for neuroplasticity and a positive attitude towards the aging brain could positively impact outcomes of cognitive interventions.

Therefore, this article describes and investigates a new public multimodal program "brain coach" aiming at supporting older adults' cognitive fitness and well-being and refining the attitude towards the aging brain. The crosssectional survey follows several aims, including to determine:

1. The age and state of health of individuals who voluntarily participate in the public program and how much time participants spend on the exercises;

2. Whether participants experience any cognitive and wellbeing-related benefits from the intervention; and

3. Whether the program can potentially facilitate autonomously engaged cognitive activities of participants and a positive attitude towards the aging brain.

Based on the findings above, the authors assume that, through an autonomy-supportive intervention, participants will feel autonomously motivated to invest time in the weekly tasks. Through the background information and regular concrete advice, they will favorably change their attitude toward the aging brain, exert more cognitively stimulating activities in their daily lives, and experience these activities' benefits.

\section{Methods}

\section{Participants}

The program began in the German-speaking part of Switzerland in March 2020. We conducted the crosssectional survey from August to October 2020. A total of 660 participants completed the survey. Inclusion criteria were met when a participant used the intervention for personal reasons and exhibited an age minimum of 60 years, resulting in 542 participants included in statistical analyses. Demographic data comprised age $(M=$ 71.47, $S D=6.34$, range: 60-92), years of education $(M=$ $13.80, S D=1.82$, range: $6-16)$, sex ( $76.2 \%$ female), civil status (3.0\% unmarried, $45.0 \%$ married, 9.0\% divorced, 9.0\% widowed, and $1.5 \%$ civil union), and health condition $(47.5 \%$ very good, $48.6 \%$ rather good, $3.7 \%$ rather bad, and $0.3 \% \mathrm{bad})$.

\section{Procedure}

The study offered a free "brain coach" program advertised in the online media and newspaper articles. Individuals registered for the intervention received a sheet with exercises and background information by email every week or every second week (length: approx. 2-5 pages). Participants were encouraged to implement the 
exercises and activities in their daily lives and exchange with other participants in an online discussion forum. They were free to choose which of the exercises they performed, when, and how intensely. After 5 months, the online survey was unannouncedly sent by email to individuals who participated in the program for at least 3 months ( $n=$ around 1500 individuals) at the date of the evaluation. Participants gave consent to participate in the study as they filled out the survey. Thus, the survey was completely voluntary and participation anonymous.

\section{Program}

Dr. Barbara Studer from the Competence Centre for Learning and Memory at the University of Bern developed the "brain coach" program in collaboration with professionals from the University of Zurich. The program takes into account findings from various applied studies that examined the effects of cognitive, emotional, social, and motivational interventions. The purpose of the program is to encourage and instruct participants to make particular activities and specific exercises part of their daily/weekly activities. Notably, the program offers exercises and background information to participants in the sense of an exercise buffet, where participants chose which tasks to execute. In addition, the authors applied self-determination theory for adult learning (i.e., autonomy, competence, and relatedness) to offer interventions supportive of individual autonomy [21]. The program consists of three parts, a collection of beneficial exercises to increase training and enablement, psychoeducative information (education), and a supervised online discussion forum (relatedness). An example of an English version of a "brain coach" exercise sheet is linked here: [https://cdn1.site-media.eu/images/document/5399492/ BraincoachProgram.pdf].

\section{Part one}

Weekly task sheet (3-6 pages) containing exercise descriptions and links to short video demonstrations of various cognitive activation exercises for everyday life. The task units are of minimal investment, approximately 5-10 min each. Thus, the participants could perform them during their daily routine. The evidence-based exercises are designed to support cognitive health by addressing five areas: memory through cognitive training tasks and memory strategies such as N-back exercises and the loci method; coordination through physical coordination tasks such as balance and juggling exercises; mindfulness through exercises for increased selfawareness such as a breathing task; creativity through generating creative new ideas such as finding new applications for an item; community through ideas for social activities without physical contact due to Covid-19; and humour through funny jokes and cartoons.

\section{Part two}

The task sheets includes psychoeducational information about brain functions and neuroplasticity. The explanations focus on the effects of the exercises and strategies on neural processes and cognitive health. Examples of topics: "Use it or lose it", how physical exercise changes our brain, lifelong learning, strategies to change habits on our own [30]. Importantly, these oral or written psychoeducative impulses are in simple words, so that little prior knowledge was needed to understand the messages.

\section{Part three}

A neuropsychologist supervised an online discussion forum. Participants were encouraged to exchange experiences, failures, and successes and ask questions answered by the neuropsychologist in the forum.

\section{Self-reported measures \\ Characteristics of participants}

Personality The Big Five Inventory, a 10-item questionnaire that records responses on 5-point Likert scales [51], measures personality traits.

Attitude towards the aging brain The study assessed participants' attitudes toward their aging brains with a five-question survey designed by the authors. One question assessed general belief in neuroplasticity, and the other four questions assessed the strength of positive and negative attitudes towards the aging brain on Likert scales ranging from 1 (no, not at all) to 4 (yes, a lot):

Belief in neuroplasticity Participants' belief in their aging brains' plasticity was assessed with the question, "What do you think about your aging brain?" Participants recorded responses on an open scale ranging from 0 (i.e., age-dependent cognitive decline) to 10 (i.e., the brain stays adaptive and capable).

Positive attitude The authors calculated the strength of positive attitude (i.e., confidence in conserved learning ability) from the mean value for the general conviction about the brain's plasticity and personal confidence in influencing cognitive fitness positively.

Negative attitude The authors calculated the strength of negative attitude (i.e., worry about cognitive decline) from the mean value of general worries about biological, age-dependent cognitive decline and individual concerns about a decline in learning and memory. 


\section{Intervention commitment}

The study assessed the frequency with which participants performed individual exercises with the question "How regularly do you perform exercises from the "brain coach" program on average?" Five answer options were available, ranging from "less than every other week" to "daily." The authors assessed weekly time invested in the exercises with the question, "How much time do you spend weekly on average doing exercises from the "brain coach" program?" The five answer options ranged from "less than $15 \mathrm{~min}$ a week" to "more than $2 \mathrm{~h}$ a week." Finally, the authors calculated the overall time invested for the intervention by multiplying the time invested in the intervention per week by the number of weeks since the participant's registration date.

\section{Perceived intervention-induced benefits}

Benefit in cognitive fitness The study asked participants about the perceived effect of the intervention on their memory performance "Have you experienced any benefit from the "brain coach" exercises for your cognitive fitness, such as memory?").

Benefit in well-being The study asked participants about the perceived effect of the intervention on their well-being (e.g., "Have you experienced any benefit from the "brain coach" exercises for your well-being, such as mindfulness, so far?"). -.

Benefit from brain health-related attitude The study asked participants whether the intervention changed their attitude toward their brain health (e.g., "Have the "brain coach" exercises changed your attitude towards your brain health?")

Benefit from activities The study asked participants whether the intervention changed their behavior (e.g., "Have you changed any activities that benefit the brain or body in everyday life because of the "brain coach" program?'). Participants reported their responses on a Likert scale ranging from 1 (no) to 4 (yes, a lot).

\section{Data analysis}

Descriptive statistical analyses were performed as mean and standard deviation and as frequency distribution for the sample characteristics, intervention commitment, and self-reported benefit of the intervention. In addition, the authors performed correlation analyses to analyze the relationship between participants' characteristics (belief in neuroplasticity, attitude towards brain health, personality), intervention commitment (total time investment), and self-reported benefits through the intervention (change in memory, mindfulness, attitude, activities). Kendall-Tau-b and Spearman's correlation coefficients were used, but only results from the former are reported here for clarity. Finally, the authors performed an analysis of multiple linear regressions to analyze the variance and the strength of the relationship between investment, attitude, and experienced profit. The dependent variable was a generalized experienced benefit, defined by the average of experienced effects on cognitive fitness and well-being and brain-health-related attitude and behavior. Two independent variables were time investment and belief in neuroplasticity.

\section{Results}

Descriptive results and frequency distributions of sample characteristics, intervention commitment, and selfreported benefit appear in Table 1 and Figs. 1, 2 and 3. In addition, correlations between these variables appear in Table 1.

\section{Time investment}

On average, participants used the intervention twice per week (Fig. 1). The average of hours invested related to the intervention was $22.31(S D=28.13)$, and the mean of weekly invested hours related to the intervention was 0.65 ( $S D=0.72$; Fig. 2). The average days of participation were 135.04 $(S D=36.75)$.

\section{Experienced benefit}

Participants described the experienced benefit of intervention as "pretty much" on the four-point Likert Scale ( $M=3.04, S D=0.56)$ with the highest benefit on the attitude towards brain health $(M=3.14, S D=0.78$; Fig. 3$)$.

\section{Time investment is related to benefit}

There was a significant relationship between time invested and benefit experienced in cognitive fitness, $r=$ .26, $p<.01$; well-being, $r=.26, p<.01$; attitude, $r=.20$, $p<.01$; and activity, $r=.29, p<.01$ (Table 1 ).

\section{Attitude toward the aging brain is related to benefit}

The belief in neuroplasticity was significantly related to benefit experienced in cognitive fitness, $r=.18, p<.01$; well-being, $r=.14, p<.01$; attitude, $r=.15, p<.01$; activity, $r=.10, p<.05$; and time investment, $r=.23, p<.01$ (Fig. 1). The regression analyses, with experienced general benefit as a dependent variable and time invested and belief in neuroplasticity as independent variables, showed a significant regression eq. $(\mathrm{F}(2,357)=34.737$, $p<.000)$, with an $R 2$ of .093. Furthermore, participants' general experienced benefit increased by 0.01 rating points for each hour of investment and by 0.136 for each rating point of belief in neuroplasticity. Thus, both time investment and belief in neuroplasticity were significant predictors of generalized benefit experienced. 
Table 1 Descriptive statistics and correlations for benefits experienced, time investment, attitudes, and big five personality traits

\begin{tabular}{|c|c|c|c|c|c|c|c|c|c|c|c|c|c|c|c|}
\hline Variables & $M$ & $S D$ & 1 & 2 & 3 & 4 & 5 & 6 & 7 & 8 & 9 & 10 & 11 & 12 & 13 \\
\hline \multicolumn{16}{|l|}{ Benefits experienced } \\
\hline 1. Cognitive Fitness & 3.01 & 0.61 & - & & & & & & & & & & & & \\
\hline 2. Well-being & 3.05 & 0.75 & $.43^{* *}$ & - & & & & & & & & & & & \\
\hline 3. Attitude & 3.14 & 0.78 & $.34^{* *}$ & $.31^{* *}$ & - & & & & & & & & & & \\
\hline 4. Activity & 2.93 & 0.81 & $.40^{* *}$ & $.40^{* *}$ & $.42^{* *}$ & - & & & & & & & & & \\
\hline \multicolumn{16}{|l|}{ Time investment } \\
\hline 5. Time Investment & 22.31 & 28.13 & $.26^{* *}$ & $.26^{* *}$ & $.20^{* *}$ & $.29^{* *}$ & - & & & & & & & & \\
\hline \multicolumn{16}{|l|}{ Attitude towards brain } \\
\hline 6. Belief in Neuroplasticity & 7.58 & 2.00 & $.18^{* *}$ & $.14^{* *}$ & $.15^{* *}$ & $.10^{*}$ & $.23^{* *}$ & & & & & & & & \\
\hline 7. Positive Attitude & 3.24 & 0.57 & $.15^{* *}$ & $.13^{* *}$ & $.16^{* *}$ & $.27^{* *}$ & $.17^{* *}$ & $.07^{\text {n.s. }}$ & - & & & & & & \\
\hline 8. Negative Attitude & 2.45 & 0.74 & $-.02^{\text {n.s. }}$ & $.00^{\text {n.s. }}$ & $-.06^{\text {n.s. }}$ & $.04^{\text {n.s. }}$ & $-.06^{\text {n.s. }}$ & $-.41^{* *}$ & $.25^{* *}$ & - & & & & & \\
\hline \multicolumn{16}{|l|}{ Personality traits } \\
\hline 9. Consciousness & 4.00 & 0.73 & $.05^{\text {n.s. }}$ & $.04^{\text {n.s. }}$ & $.06^{\text {n.s. }}$ & $.06^{\text {n.s. }}$ & $.14^{* *}$ & $.19^{* *}$ & $.06^{\text {n.s. }}$ & $-.16^{* *}$ & - & & & & \\
\hline 10. Agreeableness & 3.67 & 0.69 & $.05^{\text {n.s. }}$ & $.14^{* *}$ & $.06^{\text {n.s. }}$ & $.06^{\text {n.s. }}$ & $.12^{* *}$ & $.14^{* *}$ & $.08^{\text {n.s. }}$ & $-.04^{\text {n.s. }}$ & $.09^{*}$ & - & & & \\
\hline 11. Neuroticism & 2.71 & 0.87 & $-.09^{*}$ & $-.06^{\text {n.s. }}$ & $-.08^{\text {n.s. }}$ & $-.07^{\text {n.s. }}$ & $-.10^{*}$ & $-.20^{* *}$ & $.02^{\text {n.s. }}$ & $.12^{* *}$ & $-.11^{* *}$ & $-.21^{* *}$ & - & & \\
\hline 12. Extraversion & 3.26 & .98 & $.11^{*}$ & $.08^{\text {n.s. }}$ & $.06^{\text {n.s. }}$ & $.08^{\text {n.s. }}$ & $.09^{*}$ & $.23^{* *}$ & $.09^{*}$ & $-.12^{* *}$ & $.16^{* *}$ & $.11^{* *}$ & $-.16^{* *}$ & - & \\
\hline 13. Openness & 3.75 & 0.89 & $-.02^{\text {n.s. }}$ & $.10^{*}$ & $.11^{*}$ & $.06^{\text {n.s. }}$ & $.09^{*}$ & $.15^{* *}$ & $.14^{* *}$ & $-.08^{*}$ & $.11^{* *}$ & $.12^{* *}$ & $-.11^{* *}$ & $.15^{* *}$ & - \\
\hline
\end{tabular}

$n$ sample size, $M$ mean, $S D$ standard deviation

n.s. $p>0.05 .{ }^{*} p<0.05$. ${ }^{* *} p<0.01$

\section{Discussion}

To our knowledge, this is the first study that investigates a multimodal public online program to foster cognitive activation and health behavior of older adults. It is of considerable length and tailored to life circumstances that have changed in the Covid-19 pandemic. The "brain coach" program applies the conceptual framework that cognitive health is positively related to an active lifestyle that integrates physical, cognitive, and social activities. It is an autonomy-supportive program that aims to enable older adults by increasing their autonomous motivation and competence through education, training, and relatedness. Participants receive information about how everybody can influence their brain health and choose cognitively stimulating activities and exercises. They also receive messages encouraging them to make these choices part of their daily routine and exchange their experiences with others. This cross-sectional study reveals

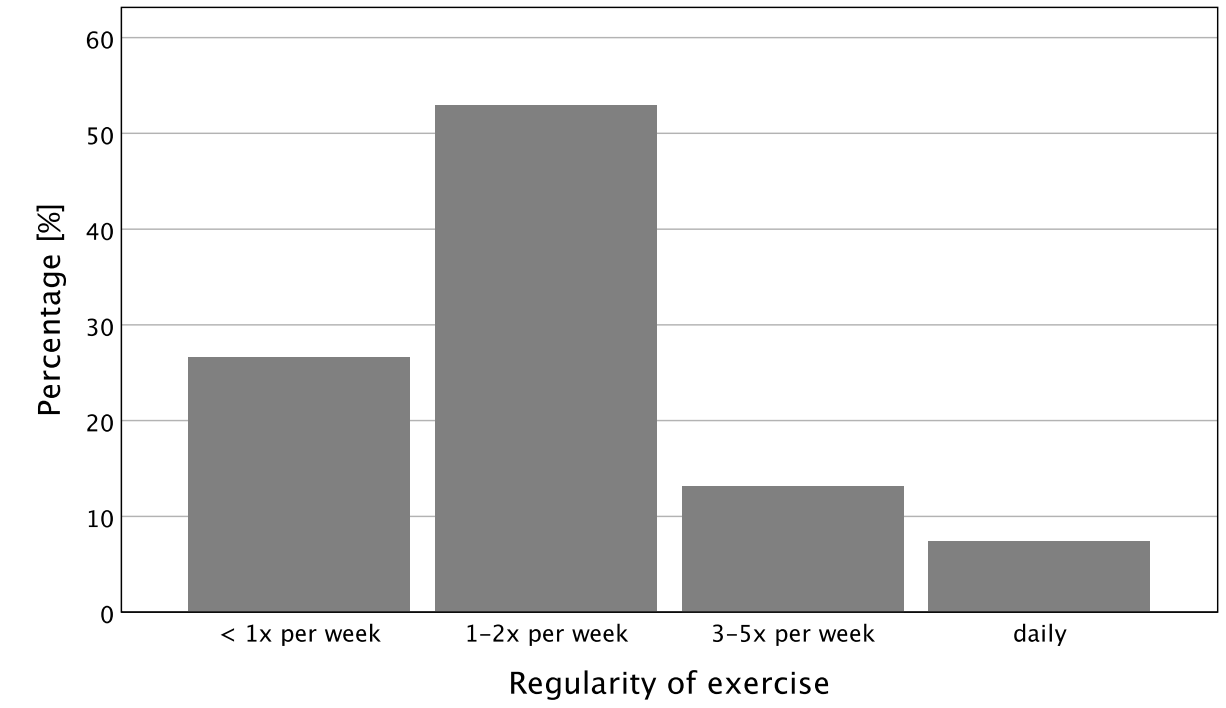

Fig. 1 Regularity of exercise on a temporal scale 


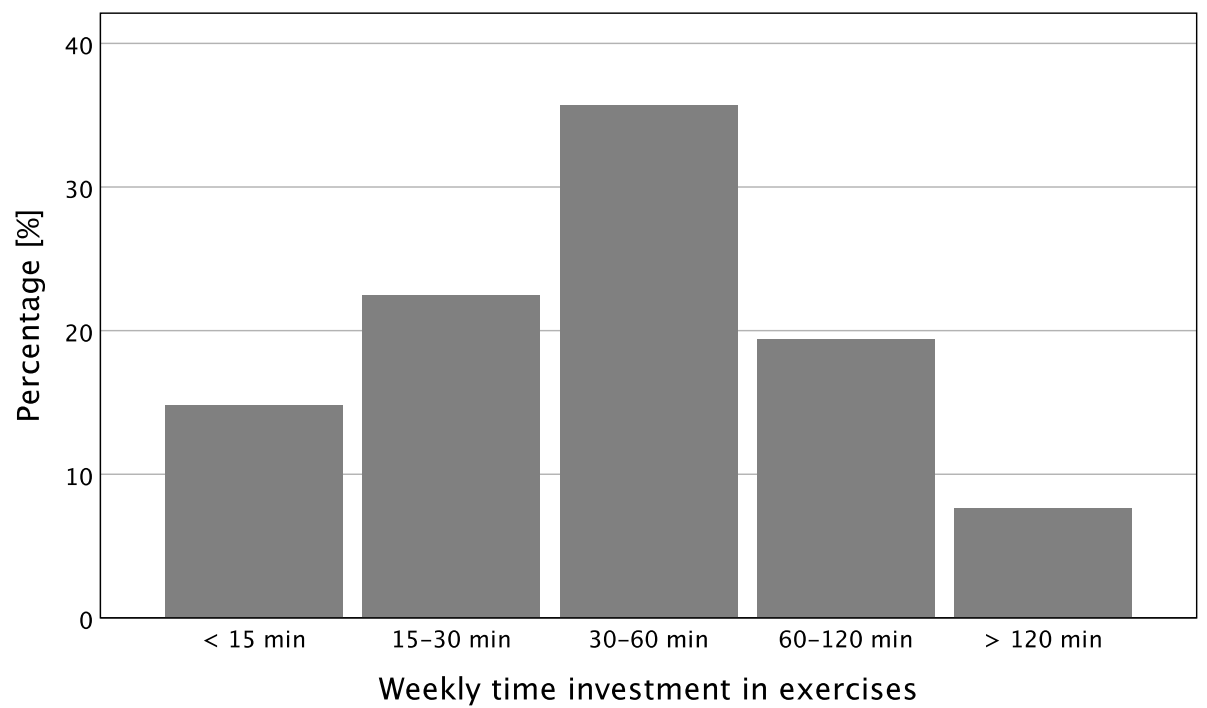

Fig. 2 Weekly time investment in exercise

the characteristics of the participants, the degree of commitment to the offered program, and the benefit experienced from it: Mean age of the participants was 71 years, $75 \%$ were female, they invested $30-60 \mathrm{~min} /$ week in the activities of the program, and they reported experienced benefits in cognitive fitness, well-being, and attitude towards their brain, and more cognitive activities in their daily life. These benefits showed positive relationships with time invested in the intervention and participant's positive attitude toward brain health and neuroplasticity.

\section{Characteristics of participants}

The mean age of participants was 71 years. This age is in line with the finding that older people's worries about their memory and dementia are highest around age 70 (see [10]). However, a recent review found inconclusive results about the influence of age on worries about dementia [70]. In addition, three-quarters of the participants were female. The gender distribution is comparable with memory and health intervention studies, where $79 \%$ or even $82 \%$ of at-risk older participants were female [43, 57]. Other findings confirm that women are more concerned about their health and about developing dementia, engage in more healthpromoting behaviors, and seek preventive healthcare measures more often (see [50], for a review). Also, the findings align with prior research showing that women tend to be more likely than men to prefer unsupervised

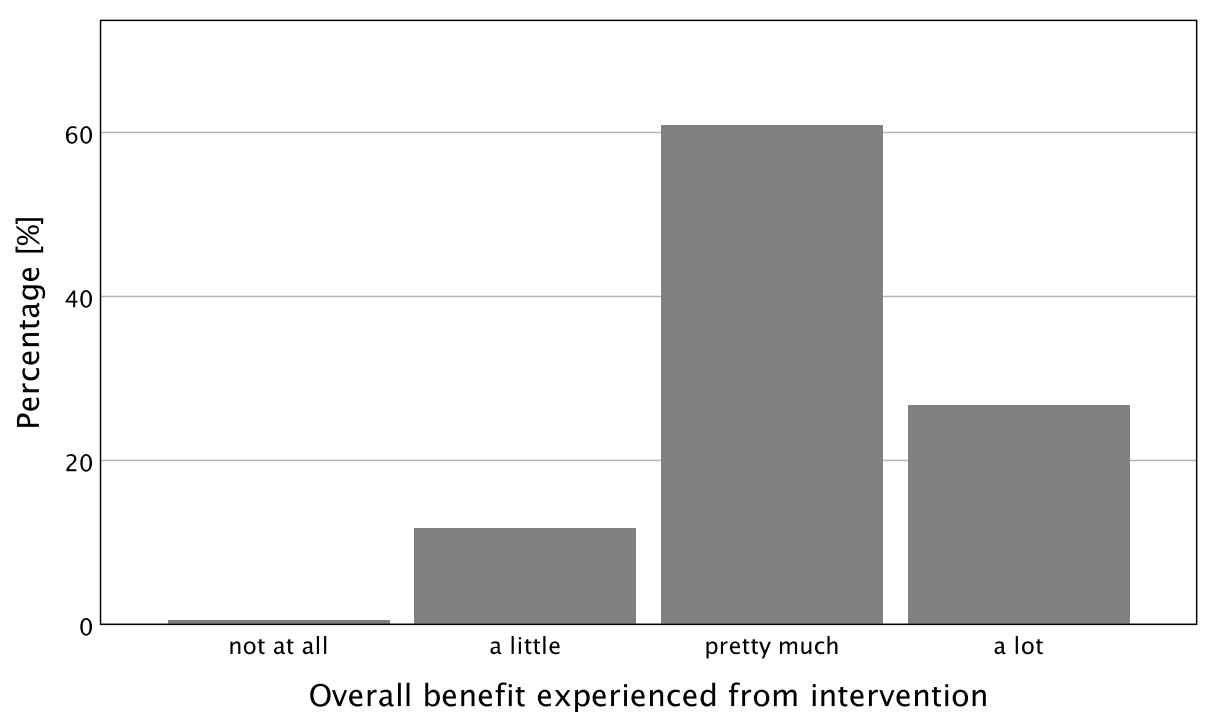

Fig. 3 Overall benefit experienced from intervention represented in verbal categories 
activities and activities at unspecified time [65]. Several explanations could account for the gender differences. These include women's greater willingness and ability to take care of themselves when they are sick, several stereotypical masculine behaviors, and men's inclination to self-reliance, physical toughness, and emotional control (cf. [50]). However, there is no consensus regarding whether men or women benefit more from interventions (see $[7,59]$, for reviews). Our sample showed no difference between males and females in intervention-related benefits $(t(367)=; 0.70, p>.05$.).

More than $90 \%$ of the participants were in good or excellent health. Good health is not surprising because the intervention was noncommittal and online and not restricted, for instance, to a health care facility. Consequently, only individuals with access to the internet and sufficient mental and self-regulation resources to implement the exercises independently could participate. In addition, other research has demonstrated that perceived health status influences participation in health promotion behavior [57].

\section{Intervention commitment}

The average weekly time invested in exercises was around $50 \mathrm{~min}$, performed on average twice per week. This time investment suggests that intervention commitment was relatively high and confirms the animating effect of the intervention. It is also in line with other interventions in older adults, which elicited between one and three home exercise sessions per week on average (cf. [49]). Finally, it corresponds to the suggested intensity of lifestyle intervention activities [29].

\section{Self-reported perceived benefits and time investment}

Generally, temporal change presents a significant stressor for older adults' well-being and may have affected participants during the time frame of the intervention. For example, the stress associated with the COVID-19 lockdown (in Switzerland from March to April 2020) restricted movement and created social isolation. In addition, as a corresponding survey shows, the global pandemic had some adverse effects on older adults' emotional well-being and loneliness ([37]).

Nevertheless, around $60 \%$ of the participants estimated that they benefitted substantially from the intervention, and more than $25 \%$ reported very high benefits. Because this survey was cross-sectional, retrospective bias cannot be excluded, and causal interpretations cannot be made. Nevertheless, the result suggests that participants experienced positive effects from the exercises introduced in the intervention. The evidence that supports this claim is the finding that self-reported benefits related closely to the time invested in intervention-related exercises. This finding confirms that the higher the inactive investment lifestyle, the higher the benefits experienced over time (cf. [32]).

Finally, participants experienced comparable positive effects on their memory performance, well-being, attitude towards their brain health, and activities in daily life. This finding confirms that interventions integrating recommendations and instructions of evidence-based exercises and lifestyle activities for cognitive health exert a positive effect on cognition and also on well-being, and lifestyle activities (e.g. [27, 29, 47]). The participant's experience of positive change in attitude towards their brain is in line with findings suggesting that brief exposure to aging stereotype content can change the levels of dementia worry ([45]). These findings indicate that addressing aging stereotypes (e.g. forgetfulness) and informing about neuroplasticity may be one way of increasing positive attitude towards cognitive health and decreasing dementia worry.

\section{Relationship between attitude towards brain health and intervention outcomes}

Individuals with a stronger belief in neuroplasticity indicated higher time investment in the intervention-related exercises and reported higher benefits experienced in cognitive fitness, well-being, attitude, and activity. This finding corroborates studies demonstrating that individuals with positive age stereotypes show less and slower cognitive decline than individuals with negative stereotypes $[35,36]$. Thus, a positive attitude to brain health may promote a willingness and motivation to invest in healthy behavior and protect cognitive health.

\section{Limitations and outlook}

The main limitation of this study is the cross-sectional method, which precludes any conclusions about causalities and intervention effects (cf. [28]). Also, all measures were self-reported and therefore prone to bias and social desirability [72]. Furthermore, we do not have any information about the individuals who participated in the program but did not follow our call to complete the survey. Therefore, we do not know if there is any systematic difference between persons who may have left the study or who continued participation but did not fill out the questionnaire instead of those who continued participation and filled out the questionnaire. It is possible that individuals not participating in the survey could be more inactive or could have experienced fewer effects of the intervention. Finally, the external validity of the findings may be low because the study occurred online, within a specific context of a developed country in Western Europe, and most participants describe their health as "rather good" or "good". The results may not be generalizable to participants with lower health or socioecological context or from countries that may not have 
access to internet-based interventions or other resources (cf., [3]).

Future research should conduct more longitudinal randomized control trials with large samples of subjects to evaluate the effects of lifestyle interventions, applied at different stages of life, on cognitive performance, wellbeing, as well as real-life changes.

\section{Conclusions and implications}

The cross-sectional survey of this autonomy supportive multimodal "brain coach" program demonstrates that participants seem to be autonomously motivated to execute the exercises, weekly invest more than $30 \mathrm{~min}$ for it, and profit from it. That is, the public program animated healthy older adults, primarily female, to invest in their cognitive health and to favorably change their attitude towards the aging brain. Participants experienced the resulting benefits in their daily lives through increased cognitive performance and well-being. The results reveal the potential of a multimodal approach, which integrates five instead of only two areas, as implemented in previous studies (e.g., cognitive and physical exercise; [34], to increase cognitive abilities, well-being, attitude towards the brain, and stimulating activities in daily life. That is, public lifestyle interventions should effectively communicate scientific evidence about the impact of an active lifestyle with physical, cognitive, social, mindful, and creative activities, on preventing cognitive decline.

Older adults seem to appreciate and profit from the autonomy supportive opportunity to choose a preferred exercise from an offered selection of activities and beneficially integrate these into their daily lives. This finding aligns with prior research that the perceived autonomy is crucial for older people, whose ability lessens with age, yet perceived autonomy increased their quality of life and satisfaction with daily routines [69]. However, this intervention appears to address women more than men. More research is needed to determine how to motivate men to invest in their cognitive health and tailor interventions to meet gender-specific interests.

Considering that the identification of factors increasing the effects of cognitive prevention programs in older adults is a prerequisite for successful prevention, our findings may have implications for implementation of such programs. That is, our findings highlight the importance of participants' attitudes toward brain health to their investment in behavior that protects cognitive health. The attitude towards the aging brain could be assessed prior to an intervention to tailor transferred information about the aging brain. Moreover, it seems necessary at a societal level to find ways to promote positive age stereotypes and attitudes towards the aging brain. Neuropsychoeducative information, such as about the neuroplasticity of the aging brain, should always be part of cognitive intervention programs. Recommendations could be personalized to participants' lifestyles and attitudes towards brain health to maximize their utility (cf. [7]). Furthermore, lifestyle interventions should occur early as possible to protect older adults' brains before impairment occurs.

In sum, our study indicates that an autonomy supportive lifestyle intervention for cognitive health which offer a choice of evidence-based exercises and activities can increase the frequency of cognitively stimulating activities executed in daily life and the experienced cognitive fitness and well-being. Increasing individual's awareness of the brain's capacity for plasticity and the resulting importance of cognitive stimulation may motivate people to adopt and maintain a cognitively active lifestyle.

\section{Abbreviations}

Covid-19: Coronavirus disease of 2019; WHO: World Health Organization

\section{Acknowledgements}

We thank Prof. Dr. Martin Meyer for his consultation.

\section{Authors' contributions}

BSL: data collection and writing of the manuscript. RS: data collection, literature research, method description. $\mathrm{MB}$ : literature research, writing of the manuscript. SL: statistical analyses and writing of results. The authors read and approved the final manuscript.

Funding

No fundings.

\section{Availability of data and materials}

The datasets used and analysed during the current study are available from the corresponding author on reasonable request.

\section{Declarations}

Ethics approval and consent to participate

The ethics committee of the University of Bern has approved the study. The ethic committee's Uni Approval Code is 2015-3-1213381.

All participants agreed at the beginning of the questionnaire to give their answers anonymously.

Consent for publication

Not applicable.

\section{Competing interests}

There is no commercial interest in the described intervention, therefore no conflict of interest to declare.

\section{Author details}

${ }^{1}$ University of Bern, Bern, Switzerland. ${ }^{2}$ University of Zürich, Zürich, Switzerland.

Received: 2 March 2021 Accepted: 3 August 2021

Published online: 16 September 2021

\section{References}

1. Abdelrahman NG, Haque R, Polverento ME, Wendling A, Goetz CM, Arnetz BB. Brain Health: Attitudes towards Technology Adoption in Older Adults. Healthcare (Basel, Switzerland). 2020;9(1):23. https://doi.org/10.3390/healthca re9010023.

2. Almond NM, Moulin CJ, Morrison C. Objective and subjective measures of performance in older adults undergoing a cognitive activity intervention. Healthy Aging Res. 2015;4:3. https://doi.org/10.12715/har.4.3.

3. Arjadi $\mathrm{R}$, Nauta $\mathrm{M}$, Chowdhary $\mathrm{N}$, Bockting $\mathrm{C}$. A systematic review of online interventions for mental health in low and middle income countries: A 
neglected field. Global Mental Health. 2015;2:E12. https://doi.org/10.1017/ gmh.2015.10.

4. Astrup A, Bertram HC, Bonjour JP, de Groot LC, de Oliveira Otto MC, Feeney EL, et al. WHO draft guidelines on dietary saturated and trans fatty acids: time for a new approach? BMJ. 2019;366:4137. https://doi.org/10.1136/bmj./4137.

5. Ball K, Berch DB, Helmers KF, Jobe JB, Leveck MD, Marsiske M, et al. Effects of cognitive training interventions with older adults: a randomized controlled trial. JAMA. 2002;288(18):2271-81. https://doi.org/10.1001/jama.2 88.18.2271.

6. Bambini V, Tonini E, Ceccato I, Lecce S, Marocchini E, Cavallini E. How to improve social communication in aging: pragmatic and cognitive interventions. Brain Lang. 2020;21 1:104864. https://doi.org/10.1016/j.bandl.2 020.104864 .

7. Barha CK, Falck RS, Davis JC, Nagamatsu LS, Liu-Ambrose T. Sex differences in aerobic exercise efficacy to improve cognition: a systematic review and meta-analysis of studies in older rodents. Front Neuroendocrinol. 2017;46: 86-105. https://doi.org/10.1016/j.yfrne.2017.06.001.

8. Berk LS, Felten DL, Tan SA, Bittman BB, Westengard J. Modulation of neuroimmune parameters during the eustress of humor-associated mirthful laughter. Altern Ther Health Med. 2001;7(2):62-72 74-66. https://www.ncbi. nlm.nih.gov/pubmed/11253418.

9. Bottiroli S, Cavallini E, Dunlosky J, Vecchi T, Hertzog C. The importance of training strategy adaptation: a learner-oriented approach for improving older adults' memory and transfer. J Exp Psychol Appl. 2013;19(3):205-18. https://doi.org/10.1037/a0034078.

10. Bowen CE, Kessler EM, Segler J. Dementia worry in middle-aged and older adults in Germany: sociodemographic, health-related and psychological correlates. Eur J Ageing. 2019;16(1):39-52. https://doi.org/10.1007/s10433-01 8-0462-7.

11. Buchmann N, Spira D, Konig M, Demuth I, Steinhagen-Thiessen E. Frailty and the metabolic syndrome - results of the Berlin aging study II (BASE-II). J Frailty Aging. 2019;8(4):169-75. https://doi.org/10.14283/ffa.2019.15.

12. Cacioppo JT, Adler AB, Lester PB, McGurk D, Thomas JL, Chen HY, et al. Building social resilience in soldiers: a double dissociative randomized controlled study. J Pers Soc Psychol. 2015;109(1):90-105. https://doi.org/10.1 037/pspi0000022.

13. Cations M, Radisic G, Crotty M, Laver KE. What does the general public understand about prevention and treatment of dementia? A systematic review of population-based surveys. PLOS ONE. 2018;13(4):e0196085. https:// doi.org/10.1371/journal.pone.0196085.

14. Chalfont G, Milligan C, Simpson J. A mixed methods systematic review of multimodal non-pharmacological interventions to improve cognition for people with dementia. Dementia. 2020;19(4):1086-130. https://doi.org/10.11 77/1471301218795289

15. Chieffi S, Messina G, Villano I, Messina A, Esposito M, Monda V, et al. Exercise influence on hippocampal function: possible involvement of orexin-a. Front Physiol. 2017;8:85. https://doi.org/10.3389/fphys.2017.00085.

16. Chiesa A, Calati R, Serretti A. Does mindfulness training improve cognitive abilities? A systematic review of neuropsychological findings. Clin Psychol Rev. 2011;31(3):449-64. https://doi.org/10.1016/j.cpr.2010.11.003.

17. Chopik WJ. The Benefits of Social Technology Use Among Older Adults Are Mediated by Reduced Loneliness. Cyberpsychol Behav Soc Netw. 2016;19(9): 551-6. https://doi.org/10.1089/cyber.2016.0151

18. Christelis D, Dobrescu LI. The causal effect of social activities on cognition: evidence from 20 European countries. Soc Sci Med. 2020, Jan 9;247:112783. https://doi.org/10.1016/j.socscimed.2020.112783.

19. Colcombe SJ, Erickson KI, Scalf PE, Kim JS, Prakash R, McAuley E, et al. Aerobic exercise training increases brain volume in aging humans. J Gerontol A Biol Sci Med Sci. 2006;61(11):1166-70. https://doi.org/10.1093/ gerona/61.11.1166.

20. Colombo B, Antonietti A, Daneau B. The Relationships Between Cognitive Reserve and Creativity. A Study on American Aging Population. Front Psychol. 2018;9:764. https://doi.org/10.3389/fpsyg.2018.00764.

21. Deci EL, Ryan RM. Self-determination theory: A macrotheory of human motivation, development, and health. Can Psychol. 2008;49(3):182-5. https://doi.org/10.1037/a0012801.

22. Flood M, Phillips KD. Creativity in older adults: a plethora of possibilities. Issues Ment Health Nurs. 2007, Apr;28(4):389-411. https://doi.org/10.1080/01 612840701252956

23. French DP, Olander EK, Chisholm A, Mc Sharry J. Which behaviour change techniques are most effective at increasing older adults' self-efficacy and physical activity behaviour? A systematic review. Ann Behav Med: a publication of the Society of Behavioral Medicine. 2014;48(2):225-34. https:// doi.org/10.1007/s12160-014-9593-z.

24. Glynn RW, Shelley E, Lawlor BA. Public knowledge and understanding of dementia-evidence from a national survey in Ireland. Age ageing 2017; 46(5):865-9. https://doi.org/10.1093/ageing/afx082.

25. Grossman P, Niemann L, Schmidt S, Walach H. Mindfulness-based stress reduction and health benefits. A meta-analysis. J Psychosom Res. 2004;57(1): 35-43. https://doi.org/10.1016/s0022-3999(03)00573-7.

26. Hedden T, Gabrieli JD. Insights into the ageing mind: a view from cognitive neuroscience. Nat Rev Neurosci. 2004;5(2):87-96. https://doi.org/10.1038/ nrn1323.

27. Hudes R, Rich JB, Troyer AK, Yusupov I, Vandermorris S. The impact of memory-strategy training interventions on participant-reported outcomes in healthy older adults: a systematic review and meta-analysis. Psychol Aging. 2019;34(4):587-97. https://doi.org/10.1037/pag0000340

28. Kendall JM. Designing a research project: randomised controlled trials and their principles. Emerg Med J: EMJ. 2003;20(2):164-8. https://doi.org/10.113 6/emj.20.2.164.

29. Klimova B, Valis M, Kuca K. Cognitive decline in normal aging and its prevention: a review on non-pharmacological lifestyle strategies. Clin Interv Aging. 2017;12:903-10. https://doi.org/10.2147/CIA.S132963.

30. Knittle K, Nurmi J, Crutzen R, Hankonen N, Beattie M, Dombrowski S. How can interventions increase motivation for physical activity? A systematic review and meta-analysis. Health Psychol Rev. 2018;12(3):211-30. https://doi. org/10.1080/17437199.2018.1435299.

31. Kuiper JS, Zuidersma M, Oude Voshaar RC, Zuidema SU, van den Heuvel ER, Stolk RP, et al. Social relationships and risk of dementia: a systematic review and meta-analysis of longitudinal cohort studies. Ageing Res Rev. 2015;22: 39-57. https://doi.org/10.1016/j.arr.2015.04.006.

32. Kuster OC, Fissler P, Laptinskaya D, Thurm F, Scharpf A, Woll A, et al. Cognitive change is more positively associated with an active lifestyle than with training interventions in older adults at risk of dementia: a controlled interventional clinical trial. BMC Psychiatry. 2016;16(1):315. https://doi.org/1 0.1186/s12888-016-1018-z.

33. Lamont RA, Swift HJ, Abrams D. A review and meta-analysis of age-based stereotype threat: negative stereotypes, not facts, do the damage. Psychol Aging. 2015 Mar;30(1):180-193. https://doi.org/10.1037/a0038586.

34. Law LLF, Barnett F, Yau MK, Gray MA. Effects of combined cognitive and exercise interventions on cognition in older adults with and without cognitive impairment: a systematic review. Ageing Res Rev. 2014;15:61-75. https://doi.org/10.1016/j.arr.2014.02.008.

35. Levy BR, Ferrucci L, Zonderman AB, Slade MD, Troncoso J, Resnick SM. A culturebrain link: negative age stereotypes predict Alzheimer's disease biomarkers. Psychol Aging. 2016, Feb;31(1):82-8. https://doi.org/10.1037/pag0000062.

36. Levy BR, Zonderman AB, Slade MD, Ferrucci L. Memory shaped by age stereotypes over time. J Gerontol B Psychol Sci Soc Sci. 2012, Jul;67(4):4326. https://doi.org/10.1093/geronb/gbr120.

37. Macdonald B, Hülür G. Well-Being and Loneliness in Swiss Older Adults During the COVID-19 Pandemic: The Role of Social Relationships. Gerontologist. 2021;61 (2):240-50. https://doi.org/10.1093/geront/gnaa194.

38. Maffei L, Picano E, Andreassi MG, Angelucci A, Baldacci F, Baroncelli L. Randomized trial on the effects of a combined physical/cognitive training in aged MCl subjects: the train the brain study. Sci Rep. 2017;7(1):39471. https://doi.org/10.1038/srep39471.

39. Malinowski P, Shalamanova L. Meditation and cognitive ageing: the role of mindfulness meditation in building cognitive reserve. J Cogn Enhance. 2017;1(2):96-106. https://doi.org/10.1007/s41465-017-0022-7.

40. Mallya S, Reed M, Yang L. A theoretical framework for using humor to reduce the effects of chronic stress on cognitive function in older adults: an integration of findings and methods from diverse areas of psychology. HUMOR. 2018:32:49-71.

41. Martinec R, Lera K. Movement, music and creativity in the elderly with dementia. Gerontol Geriatr Stud. 2018:4(2). https://doi.org/10.31031/GGS.201 8.04.000585

42. Masi CM, Chen HY, Hawkley LC, Cacioppo JT. A meta-analysis of interventions to reduce loneliness. Personal Soc Psychol Rev. 2011;15(3): 219-66. https://doi.org/10.1177/1088868310377394.

43. McDougall GJ Jr, Becker H, Pituch K, Acee TW, Vaughan PW, Delville CL. The SeniorWISE study: improving everyday memory in older adults. Arch Psychiatr Nurs. 2010;24(5):291-306. https://doi.org/10.1016/j.apnu.2009.11.001. 
44. McEwen BS. Allostasis and the epigenetics of brain and body health over the life course: the brain on stress. JAMA Psychiatry. 2017;74(6):551-2. https://doi.org/10.1001/jamapsychiatry.2017.0270.

45. Molden J, Maxfield M. The impact of aging stereotypes on dementia worry. Eur J Ageing. 2016;14(1):29-37. https://doi.org/10.1007/s10433-016-0378-z.

46. Morris MC, Tangney CC, Wang Y, Sacks FM, Bennett DA, Aggarwal NT. MIND diet associated with reduced incidence of Alzheimer's disease. Alzheimers Dement. 2015;11(9):1007-14. https://doi.org/10.1016/j.jalz.2014.11.009.

47. Ng TP, Nyunt MSZ, Feng L, Feng L, Niti M, Tan BY, et al. Multi-domains lifestyle interventions reduces depressive symptoms among frail and prefrail older persons: randomized controlled trial. J Nutr Health Aging. 2017; 21(8):918-26. https://doi.org/10.1007/s12603-016-0867-y.

48. Ngandu T, Lehtisalo J, Solomon A, Levalahti E, Ahtiluoto S, Antikainen R, et al. A 2 year multidomain intervention of diet, exercise, cognitive training, and vascular risk monitoring versus control to prevent cognitive decline in at-risk elderly people (FINGER): a randomised controlled trial. Lancet. 2015, Jun 6;385(9984):2255-63. https://doi.org/10.1016/S0140-6736(15)60461-5.

49. Picorelli AM, Pereira LS, Pereira DS, Felicio D, Sherrington C. Adherence to exercise programs for older people is influenced by program characteristics and personal factors: a systematic review. J Physiother. 2014;60(3):151-6. https://doi.org/10.1016/j.jphys.2014.06.012.

50. Pinkhasov RM, Wong J, Kashanian J, Lee M, Samadi DB, Pinkhasov MM, et al. Are men shortchanged on health? Perspective on health care utilization and health risk behavior in men and women in the United States. Int J Clin Pract. 2010, Mar;64(4):475-87. https://doi.org/10.1111/j.1742-1241.2009.022 90.x.

51. Rammstedt B, John OP. Measuring personality in one minute or less: a 10item short version of the big five inventory in English and German. J Res Pers. 2007;41(1):203-12. https://doi.org/10.1016/j.jp.2006.02.001.

52. Reijnders J, van Heugten C, van Boxtel M. Cognitive interventions in healthy older adults and people with mild cognitive impairment: a systematic review. Ageing Res Rev. 2013, Jan;12(1):263-75. https://doi.org/10.1016/j.arr.2 012.07.003.

53. Rogers WA, Mitzner TL. Envisioning the Future for Older Adults: Autonomy, Health, Well-being, and Social Connectedness with Technology Support. Futures. 2017;87:133-9. hhttps://doi.org/10.1016/j.futures.2016.07.002.

54. Ryan RM, Patrick H, Deci EL, Williams GC. Facilitating health behaviour change and its maintenance: Interventions based on self-determination theory. Eur health Psychol. 2008;10(1):2-5.

55. Sanjuán M, Navarro E, Calero MD. Effectiveness of cognitive interventions in older adults: a review. Eur J Invest Health Psychol Educ. 2020;10(3):22549625. https://doi.org/10.3390/ejihpe10030063.

56. Schlaff RA, Baruth M, Adams VJ, Goldufsky TM, Peters NA, Kerr G, et al. Effects of a group-based behavioral intervention on dietary behaviors in older adults. J Aging Health. 2018;30(1):105-17. https://doi.org/10.1177/ 0898264316668936.

57. Settersten L, Lauver DR. Critical thinking, perceived health status, and participation in health behaviors. Nurs Res. 2004;53(1):11-8. https://doi.org/1 0.1097/00006199-200401000-00002.

58. Sharma S, Babu N. Interplay between creativity, executive function and working memory in middle-aged and older adults. Creat Res J. 2017;29(1): 71-7. https://doi.org/10.1080/10400419.2017.1263512.

59. Stern A, Laughlin GA, Bergstrom J, Barrett-Connor E. The sex-specific association of serum osteoprotegerin and receptor activator of nuclear factor kappaB legend with bone mineral density in older adults: the rancho Bernardo study. Eur J Endocrinol. 2007;156(5):555-62. https://doi.org/10.153 0/EJE-06-0753.

60. Sweet SN, Fortier MS, Strachan SM, Blanchard CM. Testing and integrating self-determination theory and self-efficacy theory in a physical activity context. Can Psychol. 2012;53(4):319-27. https://doi.org/10.1037/a0030280.

61. Sweet SN, Fortier MS, Strachan SM, Blanchard CM, Boulay P. Testing a Longitudinal Integrated Self-Efficacy and Self-Determination Theory Model for Physical Activity Post-Cardiac Rehabilitation. Health Psychol Res. 2014; 2(1):1008. https://doi.org/10.4081/hpr.2014.1008.

62. Tennstedt SL, Unverzagt FW. The ACTIVE study: study overview and major findings. J Aging Health. 2013;25(8 Suppl):3S-20S. https://doi.org/10.1177/ 0898264313518133.

63. Tse MM, Lo AP, Cheng TL, Chan EK, Chan AH, Chung HS. Humor therapy: relieving chronic pain and enhancing happiness for older adults. J Aging Res. 2010;2010:343574-9. https://doi.org/10.4061/2010/343574.
64. UN. Population Dynamics. World Population Dynamics. World Population Prospects 2019 Revision (United Nations). 2019.

65. van Uffelen JGZ, Khan A, Burton NW. Gender differences in physical activity motivators and context preferences: a population-based study in people in their sixties. BMC Public Health. 2017;17:624. https://doi.org/10.1186/s12889017-4540-0.

66. Vemuri P, Lesnick TG, Przybelski SA, Machulda M, Knopman DS, Mielke MM, et al. Association of lifetime intellectual enrichment with cognitive decline in the older population. JAMA Neurol. 2014;71(8):1017-24. https://doi.org/1 0.1001/jamaneurol.2014.963.

67. Videler AC, Heijnen-Kohl SMJ, Wilting R, van Alphen SPJ. Differential diagnosis personality disorder versus autism spectrum disorder in older adults. Tijdschr Gerontol Geriatr. 2020;51(2). https://doi.org/10.36613/tgg.1 875-6832/2020.02.04 (Differentiele diag\&shy;nostiek van persoonlijk\&shy; heids\&shy;stoornissen en autisme\&shy;spectrum\&shy;stoornis bij ouderen).

68. Wells RE, Kerr C, Dossett ML, Danhauer SC, Sohl SJ, Sachs BC, et al. Can adults with mild cognitive impairment build cognitive reserve and learn mindfulness meditation? Qualitative theme analyses from a small pilot study. J Alzheimers Dis. 2019;70(3):825-42. https://doi.org/10.3233/JAD-1901 91.

69. Welford C, Murphy K, Wallace M, Casey D. A concept analysis of autonomy for older people in residential care. J Clin Nurs. 2010;19(9-10):1226-35. https://doi.org/10.1111/j.1365-2702.2009.03185.x.

70. Werner P, AboJabel H, Maxfield M. Conceptualization, measurement and correlates of dementia worry: a scoping review. Arch Gerontol Geriatr. 2021; 92:104246. https://doi.org/10.1016/j.archger.2020.104246.

71. Whitbourne SK, Sneed JR. "The paradox of well-being, identity process, and stereotype threat: ageism and its potential relationships to the self in later life," in Ageism: Stereotyping and Prejudice Against Older Persons, T. D. Nelson, Ed., pp. 247-274, MIT Press, Cambridge, Mass, USA, 2002.

72. Zemore SE. The effect of social desirability on reported motivation, substance use severity, and treatment attendance. J Subst AbuseTreat. 2012; 42(4):400-12. https://doi.org/10.1016/j.jsat.2011.09.013.

73. Zhang B, Chignell MH. Flattening the curve of cognitive decline: a survey of cognitive interventions for people living with dementia. Proc Int Symp Hum Factors Ergonom Health Care. 2020;9(1):110-4. https://doi.org/10.1177/232 7857920091064

74. Zhang Y, Li C, Zou L, Liu X, Song W. The effects of mind-body exercise on cognitive performance in elderly: a systematic review and Meta-analysis. Int J Environ Res Public Health. 2018;15(12). https://doi.org/10.3390/ijerph15122 791.

75. Zhao J, Li H, Lin R, Wei Y, Yang A. Effects of creative expression therapy for older adults with mild cognitive impairment at risk of Alzheimer's disease: a randomized controlled clinical trial. Clin Interv Aging. 2018;13:1313-20. https://doi.org/10.2147/CIA.S161861.

76. Zubala A, MacGillivray S, Frost H, Kroll T, Skelton DA, Gavine A, Gray NM, Toma M, Morris J. Promotion of physical activity interventions for community dwelling older adults: A systematic review of reviews. PloS one. 2017;12(7):e0180902. https://doi.org/10.1371/journal.pone.0180902.

\section{Publisher's Note}

Springer Nature remains neutral with regard to jurisdictional claims in published maps and institutional affiliations.

Ready to submit your research? Choose BMC and benefit from:

- fast, convenient online submission

- thorough peer review by experienced researchers in your field

- rapid publication on acceptance

- support for research data, including large and complex data types

- gold Open Access which fosters wider collaboration and increased citations

- maximum visibility for your research: over $100 \mathrm{M}$ website views per year

At BMC, research is always in progress.

Learn more biomedcentral.com/submissions 